\title{
Computed tomography-guided bronchoalveolar lavage in idiopathic pulmonary fibrosis
}

\author{
C Agustí, A Xaubet, P Luburich, MC Ayuso, J Roca, R Rodriguez-Roisin
}

\begin{abstract}
Background - High resolution computed tomography (HRCT) is now recognised as a sensitive tool for predicting the histological characteristics of the lung parenchymal abnormalities in patients with idiopathic pulmonary fibrosis (IPF). A reticular pattern on HRCT scanning is indicative of fibrotic histology while a ground glass pattern has been associated with inflammatory disease. The purpose of the present study was to investigate whether the cell population in the bronchoalveolar lavage (BAL) fluid from different lobes differs according to HRCT characteristics in patients with IPF.
\end{abstract}

Methods - Twenty six patients with IPF (18 men) of mean (SE) age 67 (2) years were included in the study. A semiquantitative analysis of the extent of the abnormalities on the HRCT scan was applied by summing the proportion of both reticular and ground glass patterns in each lobe (expressed as percentage of total area evaluated) and $100 \mathrm{ml}$ double BAL was then randomly performed in the lobe with the most extensive involvement (lobe $A$ ) and that with the least extensive involvement (lobe B).

Results - Twenty three of the 26 patients $(88 \%)$ had an abnormal cell count in the BAL fluid from lobe A compared with 18 patients $(69 \%)$ with abnormalities in the BAL fluid from lobe $B$. The median (range) percentage of $8.5 \%(0-34 \%)$ and the absolute numbers of neutrophils $(1.3 \times$ $\left.10^{4} / \mathrm{ml}, 0-14.6 \times 10^{4} / \mathrm{ml}\right)$ in lobe A were significantly higher than those in lobe $B(5 \%$ $(0-26 \%)$ and $1.2 \times 10^{4} / \mathrm{ml}\left(0-5 \times 10^{4} / \mathrm{ml}\right)$, respectively). The percentage $(3 \%, 0-19 \%)$ and absolute numbers $\left(0.65 \times 10^{4} / \mathrm{ml}, 0-4 \times\right.$ $10^{4} / \mathrm{ml}$ ) of eosinophils were also higher in lobe $A$ than in lobe $B(1 \%(0-12 \%)$ and 0.1 $\times 10^{4} / \mathrm{ml}\left(0-4.8 \times 10^{4} / \mathrm{ml}\right)$, respectively). For the group as a whole a correlation was found between the percentage and absolute numbers of neutrophils in the BAL fluid and the total score of abnormalities on the HRCT scan in the most involved lobe (lobe $A$ ). Multiple regression analysis indicated that both the percentage and absolute numbers of neutrophils were significantly and independently related to the extent of ground glass pattern.

Conclusions - In patients with IPF the cell population in the BAL fluid is not homogeneous and seems to be related to the characteristics of the abnormalities on the HRCT scan present in the lavaged lobe.

(Thorax 1996;51:841-845)
Keywords: alveolitis, high resolution CT scanning, interstitial lung fibrosis.

Idiopathic pulmonary fibrosis (IPF) is a chronic progressive disorder of the lung parenchyma manifested by both inflammation (alveolitis) and fibrosis. ${ }^{1}$ There is ample evidence to suggest that alveolitis is the earliest manifestation of IPF since its cells are responsible for the derangement of the connective tissue matrix and the subsequent development of fibrosis. ${ }^{2-4}$ Bronchoalveolar lavage (BAL) provides a safe, repeatable, and minimally invasive method of sampling inflammatory cells of the lungs. ${ }^{5}$ Several reports have suggested that the analysis of the cellular constituents retrieved from BAL fluid could provide information regarding the inflammatory activity of the disease and therefore the prognosis. ${ }^{5-14}$ Bronchoalveolar lavage has usually been performed on the middle lobe or lingula in patients with IPF, although some authors prefer the right lower lobe as IPF predominantly affects the bases of the lung. ${ }^{9}{ }^{10}$ A major concern related to the use of BAL in IPF is whether lavaging one lobe is representative of the interstitial lung disorder, based on the assumption that the inflammatory process is uniform throughout the lung parenchyma. It is clear from ventilation-perfusion scanning, gallium-67 scans, and open lung biopsies that inhomogeneity of lung involvement frequently occurs, some studies having shown a lack of uniformity of cells in BAL fluid from different lung zones. ${ }^{15}$ Thus, the results obtained with BAL may misrepresent the degree of underlying interstitial inflammation by sampling a relatively non-involved area of lung. ${ }^{16}$

High resolution computed tomography (HRCT) is now recognised as a sensitive means of identifying disease in IPF. ${ }^{17}$ Different studies have shown that the appearance of the HRCT scans can predict histological patterns made evident in open lung biopsy specimens. Both reticular and honeycombing patterns correlate with fibrosis, whereas a ground glass pattern identifies zones of alveolar and interstitial inflammation. ${ }^{18-20}$

The capacity of the HRCT scan to reflect the histopathological substrate of the lung parenchyma in IPF may help to define the role of BAL in this disease. It is our contention that the characteristics of the cell population in the BAL fluid may differ according to the extent and type of abnormalities of the lavaged lobe. To investigate this hypothesis we have applied a semiquantitative analysis of the extent of the abnormalities on the HRCT scan and performed a double BAL - one in the lobe with 
the most prominent pulmonary abnormalities and the other in the least extensively involved lobe. The aims of the present study were to establish whether cell populations retrieved from BAL fluid from these two lung zones were comparable and to determine the relationships between the cell population in the BAL fluid and the characteristics of the HRCT scan.

\section{Methods}

PATIENTS

The population studied comprised 26 consecutive patients ( 18 men) of mean (SE) age 67 (2) years (range 49-88). Seven were smokers, two had ceased smoking at least five years before entry into study, and the remaining 17 patients had never smoked. All patients had a cough and 23 had some degree of dyspnoea, with a duration of symptoms of 11 (2) months (range 0-36). Bilateral widespread crackles were heard in all patients and chest radiography showed bilateral interstitial infiltrates in all cases. The diagnosis of IPF was established by open lung biopsy in eight cases (31\%). For those 18 patients without histological confirmation of the disease two conditions were required for the diagnosis: (1) to fulfil the clinical criteria described by Turner-Warwick et al ${ }^{4}$ which we have used previously ${ }^{21} 22$ and (2) to display findings compatible with IPF on the HRCT scan. ${ }^{23}{ }^{24}$ At the time of the study none of the patients had received glucocorticoids or immunosuppressive therapy. The study was performed as part of the current diagnostic assessment and outpatient monitoring for interstitial lung diseases in our centre. ${ }^{21}$ All patients were informed of the nature of the study and gave full written informed consent. The study was approved by the ethics committee of the Hospital Clínic.

\section{PULMONARY FUNCTION TESTS}

Spirometric tests (Stead-Wells spirometer, WE Collins, Baintree, Massachusetts, USA), thoracic gas volume and airway resistance (Med Graphics System 1085, St Paul, Minnesota, USA), single breath carbon monoxide transfer factor (TLCO) (Respirameter model A; PK Morgan, Chatham, Kent, UK), and arterial blood gases at rest while breathing room air (IL 1302 Instrument Laboratories, Milan, Italy) were measured. The alveolar-arterial oxygen tension difference $\left(\mathrm{A}-\mathrm{aPO}_{2}\right)$ was calculated according to the standard formula assuming a respiratory exchange ratio $(R)$ of 0.80 . The reference values used were those from our own laboratory. ${ }^{25}{ }^{26}$ One patient was unable to perform pulmonary function tests due to senile dementia. TLCO was not performed in 12 patients and total lung capacity (TLC) in nine because of severe reduction of lung volumes and/or lack of cooperation.

\section{HIGH RESOLUTION CT SCANNING}

Computed tomographic scans were performed in either a Somaton HiQ or a Somaton Plus scanner (Siemens, Erlanger, Germany). All patients underwent conventional computed tomographic scanning of the chest using a 10 $\mathrm{mm}$ section thickness at $12 \mathrm{~mm}$ intervals.
HRCT scans were obtained at six predetermined levels: the great vessels, the aortic arch, the tracheal carina, the pulmonary hilae, the pulmonary venous confluence, and $1 \mathrm{~cm}$ above the right diaphragm. The scans were performed with a 1-2 mm section thickness and a 1-2 second scanning time during breath holding at the end of inspiration. These scans were reconstructed with a high spatial frequency algorithm and viewed at window levels appropriate for pulmonary parenchyma (mean -500 to -600 Hounsfield units; width 1400-1600 Hounsfield units).

Two radiologists (PL and MCA), without knowledge of any of the clinical, functional and radiographic findings, examined the HRCT scans. The overall extent of lobar abnormalities was scored and a semiquantitative analysis of the relative proportion (to within $10 \%$ ) of both the ground glass and the reticular patterns was performed. By consensus, two pulmonary lobes were selected - the one with the most extensive involvement (lobe $\mathrm{A}$ ) and that with the least extensive involvement (lobe $\mathrm{B}$ ).

\section{BRONCHOALVEOLAR LAVAGE}

Bronchoalveolar lavage was performed by fibreoptic bronchoscopy as previously described. ${ }^{27}{ }^{28}$ A $100 \mathrm{ml}$ lavage of sterile saline solution was performed at random in both the pulmonary lobe with the most extensive involvement (lobe $\mathrm{A}$ ) and the one less extensively involved on HRCT scanning (lobe B). The total cell count was obtained using a Neubauer s chamber and the cell viability was assessed by trypan blue dye exclusion. Differential cell counts were determined in cytocentrifuge smears (Cytospin 3, Shandon) stained with May-Grünwald Giemsa. In our laboratory, BAL differential cell counts are considered abnormal if lymphocytes are $>12 \%$, neutrophils $>3 \%$, and eosinophils $>1 \%$.

Pulmonary function tests, HRCT scans, and BAL were performed sequentially at the time of clinical diagnosis and all three procedures were carried out during an interval of less than one week.

\section{STATISTICAL ANALYSIS}

Wilcoxon's test was used for comparison of paired data and Mann-Whitney's test for unpaired data. Spearman's correlation coefficients were used for correlation analyses. A multivariate stepwise regression model was used to identify independent determinants of reticular and ground glass patterns on HRCT scans, taking the percentage and absolute numbers of the different BAL cell types separately as a dependent variable. When appropriate, a logarithmic transformation (base 10) was used to normalise BAL cell distribution. Statistical significance was established as $p \leqslant 0.05$.

\section{Results}

LUNG FUNCTION STUDIES

All patients had a moderate to severe restrictive ventilatory impairment according to spirometric tests and all but five had a TLC below $80 \%$ predicted (table 1). TLCO was below the lower 
Table 1 Mean (SE) pulmonary function test results (with range of values) of the population studied

\begin{tabular}{lll}
\hline & Actual values & \% predicted \\
\hline FVC $(1)$ & $2.2(0.2)(0.9-4.3)$ & $59(3)(28-93)$ \\
FEV $_{1}(1)$ & $1.8(0.1)(0.9-3.4)$ & $69(3)(36-97)$ \\
$\mathrm{FEV}_{1} / \mathrm{FVC}(\%)$ & & $85(4)(71-99)$ \\
$\mathrm{TLC}(1)$ & $4.4(0.2)(3.3-7)$ & $75(4)(44-107)$ \\
$\mathrm{TLCO}(\mathrm{ml} / \mathrm{min} / \mathrm{mm} \mathrm{Hg})$ & $13(1)(6-9)$ & $54(4)(26-82)$ \\
$\mathrm{Kco}(\mathrm{ml} / \mathrm{min} / \mathrm{mm} \mathrm{Hg} / \mathrm{mm})$ & $3.9(0.3)(2.4-6)$ & $78(6)(51-131)$ \\
$\mathrm{pH}$ & $7.41(0)$ & \\
$\mathrm{PaO}_{2}(\mathrm{kPa})$ & $9.3(0.3)(4.1-11.9)$ & \\
$\mathrm{PaCO}_{2}(\mathrm{kPa})$ & $4.5(0.5)(4.2-5.9)$ & \\
$\mathrm{A}-\mathrm{aPo}_{2}(\mathrm{kPa})$ & $4.9(2.2)(1.9-9.9)$ & \\
\hline
\end{tabular}

FVC $=$ forced vital capacity; FEV $_{1}=$ forced expiratory volume in one second; TLC = total lung capacity; $\mathrm{TLCO}=$ carbon monoxide transfer factor; $\mathrm{KCO}=$ carbon monoxide transfer coefficient; $\mathrm{PaO}_{2}, \mathrm{PaCO}_{2}=$ arterial oxygen and carbon monoxide tensions; $\mathrm{A}-\mathrm{aPo}_{2}=$ alveolar-arterial oxygen tension difference. limit of reference ( $80 \%$ predicted) in all but one patient, while the transfer coefficient (KCO) was below $80 \%$ predicted in seven. Arterial blood gases were performed in all but one patient. Arterial hypoxaemia $\left(\mathrm{PaO}_{2}<10.7\right.$ $\mathrm{kPa}$ ) was present in 18 patients whilst the $\mathrm{A}-\mathrm{aPO}_{2}$ was increased $(>2.7 \mathrm{kPa})$ in 22 .

BAL CELL ANALYSIS

Table 2 shows the lobes selected for performing BAL, the individual differential cell counts in the BAL fluid, and their respective HRCT scoring analysis. As shown, BAL was performed on opposite lungs in 18 patients (69\%) and in the same lung in eight cases $(31 \%)$.

The BAL differential cell count was normal in three of the 26 patients (12\%) in lobe $A$ (nos 20,23 and 25, table 2) and in eight (31\%) in lobe $B$ (nos 6, 9, 13, 16, 17, 20, 24 and 25, table 2). Individually, the percentages of lymphocytes, neutrophils, and eosinophils were above normal limits in three (12\%), 20 $(77 \%)$, and $18(69 \%)$ patients, respectively, in lobe $\mathrm{A}$ and in two $(8 \%), 17(61 \%)$, and nine $(35 \%)$ patients, respectively, in lobe $\mathrm{B}$.

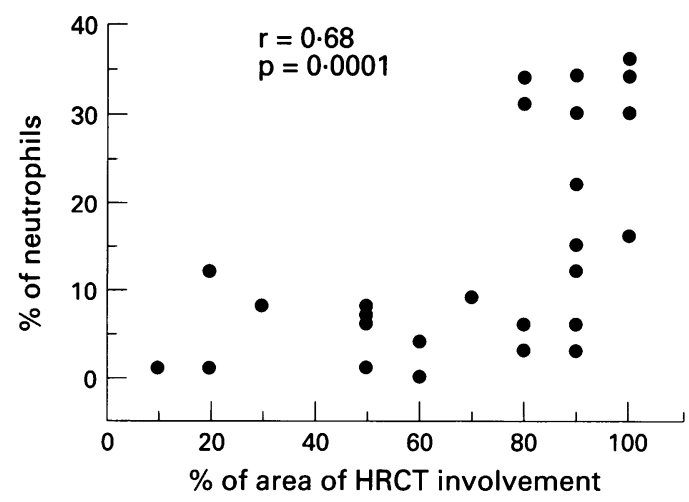

Figure 1 Correlation between percentage of neutrophils in the bronchoalveolar fluid and the extent (as a percentage of the total area of the lavaged lobe) of the pulmonary abnormalities on the HRCT scan in lobe $A(n=26)$.

A comparison of the characteristics of the BAL fluid in the two lavaged lobes (table 3) showed that the volume of liquid recovered, the number of cells, and their viability were similar, but important differences were observed when the BAL differential cell counts were evaluated. The percentage and absolute numbers of neutrophils in lobe A were significantly higher than in lobe $B(p=0.01$ for both). In lobe $A$ the percentage and absolute numbers of eosinophils were also higher than in lobe $B(p<0.01$ and $p=0.01$, respectively). The percentage of lymphocytes was similar and within normal limits in both bronchoalveolar lavages.

A correlation between both the percentage and the absolute numbers of neutrophils in the BAL fluid and the extent of total pulmonary abnormalities in the most involved lobe (lobe A) was found $\left(r_{S}=0.68\right.$ and $0.65, \mathrm{p}=0.0001$ for both) (fig 1). In contrast, no correlation was found between the extent of the abnormalities on the HRCT scan in lobe A and the percent-

Table 2 Individual topographic localisation of BAL, differential cell count and HRCT score analysis of the lavaged lobes

\begin{tabular}{|c|c|c|c|c|c|c|c|c|c|c|c|c|}
\hline \multirow[b]{2}{*}{$\begin{array}{l}\text { Case } \\
\text { no }\end{array}$} & \multicolumn{6}{|l|}{ Lobe $A$} & \multicolumn{6}{|l|}{ Lobe B } \\
\hline & Loc & $\% L$ & $\% N$ & $\% E$ & $\begin{array}{l}\text { \% } \\
\text { Ground } \\
\text { Glass } \\
\text { pattern }\end{array}$ & $\begin{array}{l}\% \\
\text { Reticular } \\
\text { pattern }\end{array}$ & Loc & $\% L$ & $\% N$ & $\% E$ & $\begin{array}{l}\% \\
\text { Ground } \\
\text { Glass } \\
\text { pattern }\end{array}$ & $\begin{array}{l}\% \\
\text { Reticular } \\
\text { pattern }\end{array}$ \\
\hline 1 & RLL & 3 & 30 & 0 & 50 & 50 & LING & 8 & 12 & 1 & 20 & 30 \\
\hline 2 & RLL & 1 & 34 & 5 & 80 & 20 & ML & 1 & 9 & 5 & 0 & 10 \\
\hline 3 & LLL & 4 & 34 & 1 & 70 & 30 & RUL & 5 & 5 & 2 & 0 & 10 \\
\hline 4 & RLL & 5 & 31 & 8 & 30 & 50 & $\mathrm{ML}$ & 1 & 11 & 3 & 0 & 10 \\
\hline 5 & LUL & 8 & 34 & 2 & 40 & 40 & LLL & 1 & 18 & 1 & 0 & 20 \\
\hline 6 & RLL & 10 & 16 & 19 & 60 & 40 & RUL & 7 & 3 & 1 & 0 & 30 \\
\hline 7 & RUL & 14 & 15 & 3 & 90 & 0 & LUL & 32 & 22 & 1 & 20 & 0 \\
\hline 8 & LLL & 8 & 34 & 3 & 50 & 50 & LING & 10 & 5 & 3 & 0 & 10 \\
\hline 9 & LING & 3 & 0 & 19 & 20 & 40 & RLL & 4 & 0 & 0 & 0 & 10 \\
\hline 10 & LLL & 4 & 6 & 9 & 30 & 50 & RUL & 2 & 3 & 2 & 0 & 10 \\
\hline 11 & LING & 5 & 12 & 2 & 80 & 10 & RLL & 1 & 17 & 0 & 10 & 10 \\
\hline 12 & LING & 4 & 22 & 2 & 30 & 60 & ML & 8 & 8 & 1 & 0 & 20 \\
\hline 13 & ML & 4 & 8 & 7 & 0 & 30 & LING & 3 & 0 & 1 & 0 & 20 \\
\hline 14 & LING & 7 & 6 & 3 & 10 & 80 & RUL & 7 & 6 & 6 & 0 & 80 \\
\hline 15 & LUL & 5 & 8 & 1 & 10 & 40 & LLL & 5 & 19 & 2 & 0 & 30 \\
\hline 16 & LING & 6 & 7 & 1 & 30 & 20 & RUL & 6 & 1 & 1 & 0 & 10 \\
\hline 17 & ML & 7 & 4 & 6 & 10 & 50 & LUL & 11 & 2 & 0 & 0 & 40 \\
\hline 18 & ML & 1 & 30 & 1 & 60 & 40 & LLL & 0 & 26 & 0 & 20 & 40 \\
\hline 19 & ML & 14 & 3 & 11 & 40 & 40 & LUL & 10 & 7 & 12 & 30 & 30 \\
\hline 20 & ML & 3 & 1 & 0 & 0 & 20 & LING & 6 & 3 & 0 & 0 & 20 \\
\hline 21 & RLL & 4 & 6 & 4 & 20 & 30 & LLL & 5 & 4 & 1 & 20 & 20 \\
\hline 22 & $\mathrm{ML}$ & 3 & 9 & 11 & 0 & 60 & LING & 1 & 11 & 10 & 0 & 40 \\
\hline 23 & ML & 2 & 3 & 0 & 10 & 70 & RUL & 1 & 4 & 0 & 10 & 50 \\
\hline 24 & ML & 18 & 1 & 10 & 0 & 10 & LING & 12 & 1 & 1 & 0 & 10 \\
\hline 25 & RLL & 6 & 1 & 0 & 10 & 40 & $\mathrm{ML}$ & 3 & 2 & 1 & 0 & 20 \\
\hline 26 & $\mathrm{ML}$ & 5 & 12 & 7 & 0 & 20 & LING & 14 & 5 & 1 & 0 & 10 \\
\hline
\end{tabular}

Abbreviations: Loc $=$ localisation, $\mathrm{L}=$ lymphocytes, $\mathrm{N}=$ neutrophils, $\mathrm{E}=$ eosinophils; $\mathrm{RUL}, \mathrm{RML}, \mathrm{RLL}=$ right upper, middle and lower lobes; LUL, LLL = left upper and lower lobes; LING=lingula. 
Table 3 Characteristics of the BAL performed on lobes $A$ and $B$

\begin{tabular}{lcllll}
\hline & \multicolumn{2}{l}{ Lobe $A$} & \multicolumn{2}{l}{ Lobe $B$} & p value \\
\hline Volume recovered $(\mathrm{ml})$ & 30 & $(17-45)$ & 32 & $(14-48)$ & NS \\
Total cells $\left(\times 10^{4} / \mathrm{ml}\right)$ & 19.5 & $(5-51)$ & 15 & $(5-77)$ & NS \\
Cell viability $(\%)$ & 75.5 & $(44-99)$ & 73.5 & $(47-99)$ & NS \\
Macrophages $(\%)$ & 77.5 & $(55-96)$ & 84 & $(43-96)$ & NS \\
Macrophages $\left(\times 10^{4} / \mathrm{ml}\right)$ & 15.1 & $(4.3-38.7)$ & 11.8 & $(3.6-73.1)$ & NS \\
Lymphocytes $(\%)$ & 5 & $(1-18)$ & 5 & $(0-32)$ & NS \\
Lymphocytes $\left(\times 10^{4} / \mathrm{ml}\right)$ & $0.77(0.2-6.8)$ & $0.70(0-7.8)$ & NS \\
Neutrophils $(\%)$ & $8.5(0-34)$ & 5 & $(0-26)$ & 0.01 \\
Neutrophils $\left(\times 10^{4} / \mathrm{ml}\right)$ & $1.3(0-14.6)$ & 1.2 & $(0-5)$ & 0.01 \\
Eosinophils $(\%)$ & 3 & $(0-19)$ & 1 & $(0-12)$ & $<0.01$ \\
Eosinophils $\left(\times 10^{4} / \mathrm{ml}\right)$ & $0.65(0-4)$ & 0.1 & $(0-4.8)$ & 0.01 \\
\hline
\end{tabular}

Values are medians (ranges). in $\mathrm{IPF}^{1}$ so that generalisations about the severity of alveolitis based on the results obtained from BAL systematically performed in one lobe may be incomplete. We have confirmed that the cell population in the BAL fluid in patients with IPF differs significantly between the different pulmonary lobes evaluated. It is important to note, however, that, in contrast to García et $a l^{15}$ who systematically compared the cell population in BAL fluid obtained from the middle lobe and the lingula, we preselected the pulmonary lobes to be explored bronchoscopically from the HRCT findings.

With the use of the HRCT scan it is possible to obtain reliable information regarding the extent and histological characteristics of the pulmonary involvement in IPF. Different studies have shown that areas of fine reticular abnormalities on the CT scan represent areas of fibrosis in the lung biopsy specimen, while areas of ground glass opacification identify an increased likelihood of an inflammatory histology ${ }^{18-20}$ Since pulmonary involvement in IPF is not homogeneous, HRCT scanning facilitates differentiation of the specific areas of the lung parenchyma to be evaluated by BAL. Our results support this contention since (1) the percentage of both neutrophils and eosinophils in the BAL fluid from the most involved areas of the lung parenchyma as determined by HRCT scanning was significantly higher, and (2) in contrast to areas of maximal involvement, the BAL cell population in those areas minimally involved was frequently within normal limits. It is accepted that both neutrophils and eosinophils play an important part in the pathogenesis of IPF by releasing oxidants, potent proteinases, and various other potentially harmful agents, ${ }^{31}$ so it is reasonable to speculate that the presence of these cells can vary according to the activity of the disease, being more abundant in areas of more extensive involvement. ${ }^{32}$

Our study also showed that BAL neutrophilia correlated with the total extent of pulmonary abnormalities on the HRCT scan and with the extent of the ground glass pattern in the lavaged lobe. These findings are supported by the fact that the inflammatory process in IPF is characterised by a sustained accumulation of neutrophils in the alveolar spaces. ${ }^{2}$ In a recent study in which patients with pulmonary fibrosis associated with systemic sclerosis were evaluated, Wells et $a l^{\beta 3}$ also showed that the percentage of neutrophils in the BAL fluid correlated with the extent of the HRCT pulmonary abnormalities in the lavaged lobe. However, in contrast with our results, they found that it was the extent of the reticular rather than the ground glass pattern that independently correlated with neutrophilia in the BAL fluid and, furthermore, they found that the percentage counts of eosinophils correlated with the extension of the ground glass pattern in the lavaged lobe. There are several explanations that could justify this apparent contradiction. Firstly, Wells et $a l^{33}$ studied a group of patients with pulmonary fibrosis associated with systemic sclerosis, possibly at an early stage of evolution of the disease since almost percentage of neutrophils between the middle lobe and the lingula. It seems evident from ventilation-perfusion scanning, gallium-67 scanning, and open lung biopsies that inhomogeneity of lung involvement frequently occurs 
$30 \%$ of the patients had no evidence of pulmonary involvement on the CT scan. It is of note, however, that both IPF and pulmonary fibrosis associated with systemic sclerosis can have a different natural history so their BAL cell profiles could be different. ${ }^{22}$ In the study by Wells et al an increase in the number of eosinophils, often without an associated neutrophilia, was observed in nine of 16 patients with limited extensive disease (less than $50 \%$ pulmonary abnormalities in the lavaged lobe) in the absence of respiratory symptoms. To explain their results they postulated that eosinophils may play a pathogenetic role in early lung disease in pulmonary fibrosis associated with systemic sclerosis. Secondly, although in the present study the use of $1 \mathrm{~mm}$ instead of $3 \mathrm{~mm}$ collimation could have improved the distinction between fibrosis and alveolitis, it seems logical that, in some cases, it is not possible to distinguish clearly between thickening of alveolar walls due to inflammatory cell infiltration and/or oedema from enhanced deposition of connective tissue; under these circumstances, areas with very fine fibrosis could not be differentiated from alveolitis. ${ }^{34}$ Thirdly, the fact that, in the present study, most of the involved lobes shared a "mixed" pattern of abnormalities (both with ground glass and reticular appearances) makes it difficult to separate the amount of each. Finally, it should be noted that a ground glass pattern may be a consequence of movement artefact. However, our patients had no difficulty in holding their breath for two seconds during HRCT scanning.

In summary, the results of our study suggest that, in patients with IPF, the cell population in the BAL fluid from different pulmonary lobes is not uniform and appears to be related to the extent of the CT abnormalities present in the lavaged lobe. The relationship between the BAL cell population and the different CT patterns, and its usefulness in expanding the knowledge of the pathogenesis of this disease, merit further evaluation.

We thank Maite Carrión and Teresa Solé for their technical expertise and Dr JM Montserrat and Dr E Ballester for their expertise and Dr JM
unselfish cooperation.

This study was supported by grant $94 / 998$ from the Fondo de Investigación Sanitaria de la Seguridad Social (FIS), the Comissionat per Universitats i Recerca de la Generalitat de Catalunya (GRQ 94/9103) and the Fundació Catalana de Pneumologia.

1 Crystal RG, Fulmer JD, Roberts WC, Moss ML, Line BR Reynolds HY. Idiopathic pulmonary fibrosis: clinical, histologic, radiographic, physiologic, scintigraphic, cytologic, and biochemical aspects. Ann Intern Med 1976; 85:769-88.

2 Keogh BA, Crystal RG. Alveolitis: the key to the interstitia lung disorders. Thorax 1982;37:1-10.

3 Carrington CB, Gaensler EA, Coutu RE, Fitzgerald MX Gupta RG. Natural history and treated course of usual and desquamative interstitial pneumonia. $N$ Engl $₹$ Med 1978; 298:801-11.

4 Turner-Warwick M, Burrows B, Johnson A. Cryptogenic fibrosing alveolitis: clinical features and their influence on fibrosing alveolitis: clinical features

5 Hunninghake GW, Gadek JE, Kawanami O, Ferrans VJ, Crystal RG. Inflammatory and immune processes in the human lung in health and disease: evaluation by bronchoalveolar lavage. Am F Pathol 1979;97:149-206.

6 Davis GS, Brody AR, Craighead JE. Analysis of airspace and interstitial mononuclear cell populations in human diffus interstitial lung disease. Am Rev Respir Dis 1978;118:7-15.

7 Haslam PL. Bronchoalveolar lavage in interstitial lun disease. Semin Respir Med 1984;6:55-70

8 Haslam PL. Cryptogenic fibrosing alveolitis: pathogenetic mechanisms and therapeutic approaches. Eur Respir $f$ 1990;3:355-7.
9 Haslam PL, Turton CWG, Lukoszek A, Collins JV, Salsbury AJ, Turner-Warwick M. Bronchoalveolar lavage fluid cell counts in cryptogenic fibrosing alveolitis and their relation to therapy. Thorax 1980;35:328-39.

10 Rudd RM, Haslam PL, Turner-Warwick M. Cryptogenic fibrosing alveolitis. Relationships of pulmonary physiolog and bronchoalveolar lavage to response to treatment and prognosis. Am Rev Respir Dis 1981;124:1-8.

11 Peterson MW, Monick M, Hunninghake GW. Prognostic role of eosinophils in pulmonary fibrosis. Chest 1987; 92:51-6.

12 Watters LC, Schwartz MI, Cherniack RM, Waldron JA Dunn TL, Stanford RE, et al. Idiopathic pulmonary fibrosis. Pretreatment bronchoalveolar lavage cellular constituents and their relationships with lung histopathology and clinical response to therapy. Am Rev Respir Dis 1987; 135:696-704.

13 Schwartz DA, Van Fossen DS, Davis CS, Helmers RA Dayton CS, Burmeister LF, et al. Determinants of progression in idiopathic pulmonary fibrosis. Am $\mathcal{F}$ Respir progression in idiopathic pulm

14 Schwartz DA, Helmers RA, Dayton CS, Merchant RK Hunninghake GW. Determinants of bronchoalveolar lavage cellularity in idiopathic pulmonary fibrosis. $\mathcal{F} A p p$ Physiol 1991;71:1688-93.

15 García JGN, Wolven RG, García PL, Keogh BA. Assessment of interlobar variation of bronchoalveolar lavage cellular differentials in interstitial lung diseases. $A m$ Rev Respir Dis 1986;133:444-9.

16 Schwartz DA, Helmers RA, Galvin JR, Van Fossen DS, Frees KL, Dayton CS, et al. Determinants of survival in idiopathic pulmonary fibrosis. Am $\mathcal{f}$ Respir Crit Care Med 1994;149:450-4

17 Wells AU, Hansell DM, Rubens MB, Cullinan P, Black CM, du Bois RM. The predictive value of appearances on thinsection computed tomography in fibrosing alveolitis. Am Rev Respir Dis 1993;148:1076-82.

18 Müller NL, Miller RR, Webb WR, Evans KG, Ostrow DN. Fibrosing alveolitis: CT-pathologic correlation. Radiology 1986;160:585-8.

19 Müller NL, Stables CA, Miller RR, Vedal S, Thurbeck WM, Ostrow DN. Disease activity in idiopathic pulmonary fibrosis: CT and pathologic correlation. Radiology 1987 165:731-4.

20 Nishimura $K$, Litaichi $M$, Izumi T, Nagai S, Kanaoka $M$, Itoh $\mathrm{H}$. Usual interstitial pneumonia: histologic correlation with high resolution CT. Radiology 1992;182:337-42.

21 Agusti C, Xaubet A, Agusti AGN, Roca J, Ramirez J Rodriguez-Roisin R. Clinical and functional assessment of patients with idiopathic pulmonary fibrosis: results of a 3 year follow-up. Eur Respir F 1994;7:643-50.

22 Agustí C, Xaubet A, Roca J, Agustí AGN, Rodriguez-Roisin R. Interstitial pulmonary fibrosis with and without associated collagen vascular disease:

23 Hansell DM, Kerr IH. The role of high resolution computed tomography in the diagnosis of interstitial lun disease. Thorax 1991;46:77-84.

24 Leung AN, Miller RR, Müller NL. Parenchymal opacification in chronic infiltrative lung diseases: CT-pathologic correlation. Radiology 1993;188:209-14.

25 Roca J, Sanchis J, Agustí-Vidal A, Segarra F, Navajas D, Rodriguez-Roisin $\mathrm{R}$, et al. Spirometric reference values from a Mediterranean population. Bull Eur Physiopathol Respir 1986;22:217-24

26 Roca J, Rodriguez-Roisin R, Cobo E, Burgos F, Pérez J, Clausen JL. Single-breath carbon monoxide diffusing capacity (DLCO) prediction equations from a Mediterranean population. Am Rev Respir Dis 1990;140:1026-32.

27 Xaubet A, Rodriguez-Roisin R, Bombi JA, Marin A, Roca J, Agustí Vidal A. Correlation of bronchoalveolar lavage and clinical and functional findings in asbestosis. Am Rev Respir Dis 1986;133:848-54.

28 Xaubet A, Agustí C, Roca J, Picado C, Rodriguez-Roisin R. BAL lymphocyte activation antigens and diffusing capacity are related in mild to moderate pulmonary sarcoidosis. Eur Respir $\mathcal{F}$ 1993;6:715-8.

29 Peterson MW, Nugent KM, Jolles $\mathrm{H}$, Monick M, Hunninghake GW. Uniformity of bronchoalveolar lavage in patients with pulmonary sarcoidosis. Am Rev Respir Dis 1988; 137:79-84.

30 Scott Miller K, Smith EA, Kinsella M, Schabel SI, Silver RM. Lung disease associated with progressive systemic sclerosis. Am Rev Respir Dis 1990;141:301-6.

31 Daniele RP, Dantzker DR, Davis GS, Hunninghake GW, King TE Jr, Metzger WJ, et al. Clinical role of bronchoalveolar lavage in adults with pulmonary disease. Am Rev Respir Dis 1990;142:481-6.

32 Turner-Warwick $M$, Haslam PL. The value of serial bronchoalveolar lavages in assessing the clinical progress of patients with cryptogenic fibrosing alveolitis. Am Rev Respir Dis 1987;135:26-34.

33 Wells AU, Hansell DM, Rubens MB, Cullinan P, Haslam PL, Black CM, et al. Fibrosing alveolitis in systemic sclerosis. Bronchoalveolar lavage findings in relation to computed tomographic appearance. Am $\mathcal{F}$ Respir Crit Care Med 1994;150:462-8.

34 Wells AU, Hansell DM, Corrin B, Harrison NK, Goldstraw $\mathrm{P}$, du Bois RM. High resolution computed tomography as a predictor of lung histology in systemic sclerosis. Thorax 1992;47:508-12. 